\title{
Characterization of the Bioactivity of Two Commercial Composites
}

\section{Melissa Tiskaya, * N.A.Al-eesa 2,3, F.S.L.Wong 2, R.G.Hill 2}

1. Queen Mary University of London, SEMS, Mile End Road London E1 4NS.

2. Queen Mary University of London, Barts \& The London School of Medicine and Dentistry, Institute of Dentistry, Centre for Oral Bioengineering, Mile End Road, London E1 4NS, UK

3. University of Anbar, Colledge of Dentistry, Department of Paediatric , Orthodontic and Preventive Dentistry, PO.Box 55 Ramadi, Iraq.

\section{Abstract}

The aim of this study was to characterize the ion release, $\mathrm{pH}$ changes and apatite formation ability of two potentially bioactive composites Cention N (CN) and Activa (ACT). Ion release and apatite formation was investigated in three different immersion media: Tris buffer pH 7.3 (TB), Artificial Saliva pH 4 (AS4) and Artificial Saliva pH 7 (AS7) in order to mimic the conditions present in the mouth. Fluoride release was followed using an ion selective electrode, whilst all other ions were determined by inductively coupled plasma optical emission spectroscopy. Apatite formation was followed by FTIR and XRD. SEM was used to follow glass degradation and apatite formation on both polished crosssections and surfaces of the composites.

ACT released very few ions including fluoride upon immersion in TB and AS7, but released more ions including significant quantities of $\mathrm{Al}$ in AS4. This would suggest the glasses in ACT are acid degradable fluoro-alumino-silicate glasses similar to the glasses used in glass ionomer cements. There was no evidence of any apatite formation with ACT.

CN released more ions in TB and AS7 than ACT and formed an apatite like phase in AS7. The calcium fluoro-silicate glass in CN was observed to degrade significantly in AS4. CN has bioactive properties that may explain the low incidence of secondary caries found clinically with this composite.

Key Words Composite Resin, Ion Release, Fluoride, Bioactive. 


\section{Introduction}

There is a need to develop a successful alternative to dental amalgam as a result of the Minamata Agreement to phase out amalgams. Existing composite resin restorations generally fail as a result of polymerization contraction, marginal leakage and secondary caries. Good clinical results can be achieved with modern day composite restoratives provided that the dentist isolates the tooth from moisture and saliva, uses a bonding agent and builds the restoration up incrementally to minimize the polymerization contraction [1-3]. However, these procedures are time consuming for the dentist and expensive for the patient. Most general dental practitioners hardly use tooth isolation techniques and build up the restoration in relative few increments, resulting in much greater polymerization shrinkage and marginal gaps. The literature indicates that in general practice most composite restorations last only about seven years [3]. Any new alternative to dental amalgams must address the real world situation and accept that any material that sets by a polymerization reaction is going to exhibit a marginal gap and be prone to secondary caries. The solution is to develop composites with reactive fillers that protect the tooth against secondary caries. These are referred to as "bioactive restoratives" discussed recently by Vallitu et al. [4] in a recent editorial in this journal.

Two commercial composite restoratives have recently been launched; $\mathrm{CN}$ and ACT. ACT is promoted as a bioactive restorative that forms apatite in the marginal gaps and is claimed to release more fluoride than glass ionomer cements. According to the manufacturer, $\mathrm{CN}$ contains three inorganic glasses: a conventional inert barium alumino-silicate glass, an ionomer glass based on a calcium barium alumino-fluoro-silicate and a basic calcium fluoro-silicate glass referred to as an "Alkasite" filler [5]. It is important to note that with ionomer glasses, degradation only occurs as a result of acid hydrolysis of Al$\mathrm{O}-\mathrm{Si}$ bonds. As a result, the ionomer glasses do not degrade significantly at $\mathrm{pH}$ $>6$ and therefore do not release significant fluoride or calcium under these conditions. $\mathrm{CN}$ is also claimed to contain ytterbium fluoride.

It is unclear what type of glass the ACT product contains. The paper by Jun et al. [6] on ACT discusses the bioactive glasses (BG) originally developed by 
Hench and reviewed by Jones [7] in the introduction, which would imply that it contains a BG. A bioactive glass is defined as a glass that dissolves in physiological solution at a neutral $\mathrm{pH}$, releasing calcium and phosphate ions and forms an apatite-like phase. Since the first step involves the ion exchange of $\mathrm{Na}_{+}$and $\mathrm{Ca}_{2+}$ ions for $\mathrm{H}_{+}$ions in solution, the $\mathrm{pH}$ rises as it dissolves. However there is no description or details from the manufacturer in the technical brochure on the glass used in this material. In contrast, the paper by Garoushi et al. [8] suggests it contains an ionomer glass in the introduction, but later in the Table describing the ACT states that it contains a bioactive glass. The manufacturer claims ACT to be a bioactive composite and form apatite in the marginal gap of restorations. The manufacturers of ACT also claim this material releases more fluoride than conventional GICs, which is not supported by the results of Garoushi et al.[8].

The purpose of this study is to investigate for the first time the full ion release, $\mathrm{pH}$ changes and apatite formation of these two new commercial composites under different conditions of immersion, reflecting the range of conditions that might be experienced in vivo. $\mathrm{CN}$ has been studied previously [8-11], but the studies have largely focused on curing, shrinkage and marginal leakage [9-11]. It is important to note that marginal leakage and secondary caries are likely to be strongly influenced by ion release, $\mathrm{pH}$ changes and precipitation of material such as apatite in the marginal gaps.

\section{Experimental}

\subsection{Materials}

ACT and $C N$ were obtained from the manufacturers. The details are given in Table 1. CN is presented as a powder, which is hand mixed with the resin by spatulation, whilst ACT comes in two pastes, which are mixed by co-extrusion through a spiral nozzle.

The experimental methods used in this study follow the procedures used by Aleesa et al. [12-14]. 


\subsection{Preparation of Composite Disks:}

The composite disks were produced using Teflon moulds of $10 \mathrm{~mm}$ diameter and $1.2 \mathrm{~mm}$ thickness. A transparent acetate sheet with a glass slabs was placed below and above the paste filled mould and a $200 \mathrm{gm}$ weight was placed to release any air bubbles and remove excess material. Then the disk was cured using 3M ESPE EliparTM light for 40 seconds.

Disks (132) for each material were produced and divided into 3 equal groups of 66 and each disk was immersed in a $15 \mathrm{~mL}$ polypropylene centrifuge tube (Fisher Scientific UK Ltd, Leicestershire, UK) containing $10 \mathrm{~mL}$ of one of the following solutions: tris buffer $\mathrm{pH}=7.3$ (TB), artificial saliva at $\mathrm{pH}=7$ (AS7) and artificial saliva at $\mathrm{pH}=4$ (AS4). These three media were chosen because TB has a better maintained $\mathrm{pH}$ than de-ionised water; AS7 and AS4 were chosen to mimic remineralising and demineralising enviorments in saliva respectively. At each of the eight time points $(0,6,24$ hours, 3, 7, 14, 28, and 42 days), Three disks from each group were removed for analysis at each time point. These disks were removed from their solution, washed and dried for investigation using attenuated total reflectance - fourier transform infrared spectroscopy (ATR-FTIR), x-ray diffraction (XRD) and scanning electron microscopy (SEM). The solutions after immersion were used for measurement of $\mathrm{pH}$ changes using a $\mathrm{pH}$ meter (Oakton Instruments $\mathrm{pH} 11$ Portable $\mathrm{pH} / \mathrm{mV}$ Meter accuracy with \pm 0.01 of a $\mathrm{pH}$ unit), and fluoride measured using an ion selective electrode (ISE) (Orion 9609BNWP with Orion pH/ISE meter 710, Thermo Scientific, Waltham, MA, USA). $\mathrm{Ca}$ and $\mathrm{PO}_{4}$ release were measured using inductively coupled plasma-optical emission spectroscopy (ICP-OES, Varian Vista-PRO, Varian Ltd., Oxford, UK). The remaining disks were washed using deionised water, dried and re-immersed in one of the three freshly made solutions until the next time point of measurement. Not replenishing the solutions would be expected to decrease the amount of orthophosphate and calcium for forming apatite. Replenishing the solution in part mimics the turnover of saliva in the mouth.

FTIR was carried out in the ATR mode on the intact disks to look for evidence of glass degradation and formation of any calcium phosphate phases on the surface of the disk. SEM was carried out on both surface and cross-sections of 
the disks. Disks were cut in two, mounted in an acrylic resin and then polished using silicon carbide papers of varying roughness (P600, P1000 and P4000) using a polishing unit (Kemet, Kent 4 Automatic Lapping and Polishing Unit) according to Al-eesa et al [12]. The samples were carbon coated for SEM.

\section{Results}

\section{Characterization of Unimmersed Disks.}

The initial disks were amorphous with the exception of diffraction peaks for ytterbium trifluoride, which were present in the $\mathrm{CN}$.

Four distinct phases are present in the polished back scattered SEM images of the $\mathrm{CN}$, corresponding to the three glass compositions and ytterbium fluoride $\left(\mathrm{YbF}_{3}\right)$, which back scatters very strongly. Figure 1 shows the back scattered SEM. There are three types of filler particles in addition to $\mathrm{YbF}_{3}$, two of which are homogenous, but back scatter differently and a third which is granular in appearance. The particle size of the glass particles in $\mathrm{CN}$ are relatively coarse with many 20-30 micron particles. The $\mathrm{YbF}_{3}$ exists as very fine particles $<1$ micron, but also appears as large particles and clusters. The distribution of both the different glass particles in $\mathrm{CN}$ and the $\mathrm{YbF}_{3}$ is somewhat heterogenous and may well reflect the hand mixing of this material.

Figure 2 shows the back scattered SEM of ACT. It contains of two types of filler particles that back scatter slightly differently, but both types of particles are much smaller ( $<10$ microns) than in the $\mathrm{CN}$ and with a much more even distribution that may reflect the helical mixing delivery system.

\section{pH Changes Upon Immersion}

Figure 3 shows the $\mathrm{pH}$ change at each time point for $\mathrm{CN}$ and ACT in TB, AS4 and AS7 respectively. The $\mathrm{pH}$ in TB increases by 0.35 upon immersion for 6 weeks for $\mathrm{CN}$, and to a lesser extent for ACT. In AS4 the $\mathrm{pH}$ also increases by about 0.2 for both ACT and $C N$ at 6 weeks. In contrast, after AS7 immersion, the $\mathrm{pH}$ reduces slightly by about 0.1 for both $\mathrm{ACT}$ and $\mathrm{CN}$ at 6 weeks. 


\section{Ion Release}

Figure 4 shows the cumulative calcium release for $\mathrm{CN}$ and ACT after TB immersion. The $\mathrm{CN}$ releases significant amounts of calcium up to $60 \mathrm{ppm}$ and the release is linear with square root time. In contrast ACT releases a total of just over $7 \mathrm{ppm} \mathrm{Ca}$ at 6 weeks. There is no significant phosphorus release for both materials. Figure $5 \mathrm{a}$ shows the $\mathrm{Ca}$ and $\mathrm{P}$ plotted cumulatively after subtracting the initial values for the $\mathrm{Ca}$ and $\mathrm{P}$ in AS4. It can be seen that there is considerably more Ca release, approximately 240ppm cumulatively at six weeks from $\mathrm{CN}$, whilst ACT releases $111 \mathrm{ppm} \mathrm{Ca}$ into AS4. There is no significant phosphorus release or consumption in AS4 for both composites. The high $\mathrm{Ca}$ release in AS4 for $\mathrm{CN}$ reflects the fact that the first step in the degradation of the glass is the ion exchange of $\mathrm{H}_{+}$ions in solution for $\mathrm{Ca}_{2}+$ ions in the glass. The higher the $\mathrm{H}_{+}$concentration or the lower the $\mathrm{pH}$, the faster the glass degradation takes place. In the case of ACT, it is probably the acid hydrolysis of Al-O-Si bonds in the ionomer glass that gives rise to the much greater $\mathrm{Ca}$ release in AS4 [15,16]. Figure $5 \mathrm{~b}$ shows the cumulative $\mathrm{P}$ lost against square root time in AS7. There is a decrease in $P$ for the $C N$ of about 40ppm indicating a loss of $P$ from solution, whilst a slight increase is observed for ACT.

Figure 6 shows the cumulative Al release for CN and ACT into TB, AS4 and AS7. here is negligible release of $A$ into TB and AS7, but significant release in AS4. The Al release occurs as a result of the acid hydrolysis of Al-O-Si bonds that doesn't occur at neutral $\mathrm{pH}[15,16]$.

Figure 7 shows the cumulative $\mathrm{Si}$ release into TB for $\mathrm{CN}$ and ACT. The release doesn't change dramatically with immersion media. However there is much more $\mathrm{Si}$ released from $\mathrm{CN}$ than from ACT. This reflects the $\mathrm{Si}$ released from the calcium fluorosilicate glass in $\mathrm{CN}$ that mirrors the $\mathrm{Si}$ release behaviour found for BGs $[17,18]$.

\section{Fluoride Release}

Figure 8 shows both $\mathrm{CN}$ and ACT composites release fluoride ions after immersion in all the media, but the amount of fluoride released in both cases is relatively low compared to acid-base set glass ionomer cements [18]. In the 
case of ACT and CN in TB and AS4, the release of fluoride has a square root time dependence suggesting a diffusion controlled release that is also typically found for GICs [18,20]. The CN releases almost twice as much fluoride as the $A C T$ and there is no significant differences in the release of fluoride for ACT in different media. The fluoride release found for ACT is similar to that found by Garoushi et al. [8] though they measured the release into water and used an 8 $\mathrm{mm}$ diameter disk compared with a $10 \mathrm{~mm}$ disk used here, and eluted into 5 $\mathrm{mL}$ as opposed to $10 \mathrm{~mL}$ used in the present study. The fluoride release into AS7 for ACT has a square root time dependence, but not, for the CN in AS7. Also, the CN releases less fluoride release in AS7 than in TB that suggesting either a different mechanism of release or possibly some of the released fluoride being consumed to form fluorapatite $\left(\mathrm{Ca}_{5}\left(\mathrm{PO}_{4}\right)_{3} \mathrm{~F}\right)$ or calcium fluoride $\left(\mathrm{CaF}_{2}\right)$.

\section{ATR-FTIR}

Figure 9a shows the ATR-FTIR spectrum of CN after immersion in TB. There is a progressive loss in absorbance at $900-960 \mathrm{~cm}-1$ corresponding to the loss of non-bridging oxygen (NBO) vibrations [21]. There is no evidence of any vibrations associated with calcium orthophosphate formation at 560 and 600 $\mathrm{cm}-1$. The glasses in $\mathrm{CN}$ contain no significant amounts of phosphate and the Tris buffer contains no phosphate, consequently it is not possible to form any calcium orthophosphate phase, including apatite like phases.

Upon immersion in AS4 (Figure 9b) there are similar changes observed in the FTIR spectra. Again, there is no evidence of any calcium orthophosphate formation despite phosphate being present along with calcium in the immersion solution. Here the $\mathrm{pH}$ is probably too low to form an apatite as the $\mathrm{pH}$ data indicates the $\mathrm{pH}$ did not raise over 4.5 which is where a fluorapatite would start to form.

In AS7 (Figure 9c) there is again evidence for the loss of NBO vibrations, but there is also evidence for the formation of a calcium orthophosphate with P-O absorbance bands at 568 And $607 \mathrm{~cm}-1$ [21-23]. These bands increase in intensity with increasing immersion time. At the same time the band at 1731 $\mathrm{cm}-1$, associated with the carbonyl groups $(\mathrm{C}=\mathrm{O})$ of the resin, reduces in intensity. This signal corresponds largely to the UDMA component of the resin. 
The orthophosphate formed could be either tricalcium phosphate claimed by the manufacturer or an apatite like phase.

The FTIR spectra (Figure 10) of ACT do not exhibit any significant changes upon immersion. There are some small increases in intensity in the range 1025$1075 \mathrm{~cm}-1$ and $1130-1170 \mathrm{~cm}-1$ upon immersion in all media. There is no evidence of any split bands at approximately 560 and $600 \mathrm{~cm}-1$ for calcium orthophosphate. ACT exhibited an amorphous diffraction pattern both before and after immersion in all media for all times. There was no evidence of any apatite formation after six weeks immersion in AS7 or after immersion in the other immersion media.

Figure 11 shows the XRD pattern of $\mathrm{CN}$ before and after immersion in AS7 for two and six weeks. The $\mathrm{CN}$ before immersion shows sharp diffraction lines at 24.63, 26.27, 28.01 and 31.75o two theta corresponding to Ytterbium trifluoride $\mathrm{YbF}_{3}$ (PDF 34-0102). After immersion, at 2 weeks and 6 weeks, there are new diffraction lines corresponding to an apatite including fluorapatite (PDF 15-876). The diffraction line at $\approx 25.8$ o two theta corresponding to the 002 spacing is particularly strong after two weeks immersion and the diffraction lines between 31 and 34o two theta are also present. This would suggest that $\mathrm{CN}$ is forming apatite, rather than tricalcium phosphate as claimed by the manufacturer. Though at this stage, it cannot be determined whether the apatite is a hydroxyapatite, a fluorapatite, a mixed fluorohydroxyapatite, or even octacalcium phosphate. Given the release of fluoride based on similar fluoride bioactive glasses, it is expected to be a fluorapatite [24-26]. At six weeks the 002 diffraction is particularly intense and indicates the apatite is forming with the c-axis perpendicular to the surface of the disk. This phenomena has also been observed by Aleesa et al. [12] with fluoride bioactive glass composites, and highly aligned needle like fluorapatite crystals are also observed by SEM. There was no evidence in the XRD data of calcium fluoride forming upon immersion. Aleesa et al. [12] have shown using ${ }_{19} \mathrm{~F}$ MAS-NMR that the fluoride bioactive glass they studied forms calcium fluorapatite in AS7 and also some $\mathrm{CaF}_{2}$ in AS4. However in the present case because of the presence of $5-10 \%$ of $\mathrm{YbF}_{3}$ which is paramagnetic, ${ }_{19} \mathrm{~F}$ MAS-NMR is not a useful technique here. 
No significant changes were observed in the XRD patterns upon immersion in Tris Bufffer or AS4.

\section{SEM of Immersed Disks}

Immersion of $\mathrm{CN}$ for six weeks in TB results in a loss of the back scattered intensity in the surface layer of the composite disk up to about 30 microns deep. This occurs primarily from the calcium fluorosilicate glass particles. After immersion in AS4 for six weeks the reacted layer is much more obvious and much more clearly demarcated and about 30-40 microns thick. The reacted layer contains two types of reacted glass particles that may indicate that both the ionomer type glass and the calcium fluorosilicate glass have reacted in the surface layer. The barium boro-alumino-silicate inert glass appears to have been mixed with resin and $\mathrm{YbF}_{3}$ polymerised, ground up and incorporated back into the composite. It has a speckled appearance which doesn't change upon immersion in AS4. In AS7, CN shows evidence of the reaction of the glass particles at the surface though to a much lesser extent than the samples immersed in AS4. However there is no obvious calcium phosphate layer formed on the surface of the $\mathrm{CN}$ despite its detection by XRD and FTIR. It could be possible that an apatite layer has formed but it is weakly bonded to the surface and easily lost during the grinding and polishing procedure used in sample preparation.

There are no observable changes in the surface of ACT in any of the immersion media when imaged by SEM.

The surface of the Cention disk after immersion in AS7 for six weeks is shown in Figure 13. Randomly orientated plate like crystals were observed, approximately 1-5 microns across and 0.1-0.3 microns thick.

\section{Discussion}

Analysis of the $\mathrm{CN}$ is complicated by the presence of three different glass compositions in the composite, plus the presence of ytterbium fluoride, howevever the active glass in $\mathrm{CN}$ is a calcium fluorosilicate glass, that is compositionally and mechanistically similar in its degradation behaviour to bioactive glasses [1]. This glass, unlike the majority of bioactive glasses, 
contains no phosphate [5]. This contrasts with the bioactive glasses composites studied in the literature to date that contain phosphate [27-30].

$\mathrm{CN}$ and ACT both increase the $\mathrm{pH}$ upon immersion in TB and AS4. In the case of $\mathrm{CN}$, particularly in TB, this is probably due to the ion exchange of $\mathrm{Ca}_{2}+$ for $\mathrm{H}_{+}$ ions in a similar fashion to $B G$ and $B G$ composites [1]. The increase in the $\mathrm{pH}$ would also be expected to occur in marginal gaps and would be expected to inhibit the growth of acidophyllic bacteria associated with caries.

Eden [31] and O'Donnell et al. [32] have shown that the amount of apatite formed and the speed of apatite formation increase with the phosphate content of the bioactive glass. Whilst Mneimne et al. [33] have shown that Fluoride containing BGs with high phosphate give faster formation of fluorapatite. Furthermore Mneimne et al. [33] demonstrated fluorite formation is supressed in high phosphate bioactive glasses. There are compositional similiarities between the calcium fluorosilicate glass used in $\mathrm{CN}$ and the BG composites studied by Aleesa et al.[12] recently. It is not possible to compare directly, however, based on the EDAX analysis the calcium fluorosilicate glass in CN, it is thought to be close to example 7 in the patent assigned to Ivoclar [34] (see Table $2[35,36])$. Therefore, the basic active glass in $\mathrm{CN}$ is similar to the glass studied by Aleesa et al., but lacks the $\mathrm{P}_{2} \mathrm{O}_{5}$ content and the ability to release orthophosphate ions for apatite formation.

Apatite formation by $\mathrm{CN}$ is dependant on the availability of orthophosphate from the external media. In the absence of sufficient orthophosphate, it will have a tendency to form $\mathrm{CaF}_{2}$. $\mathrm{CN}$ cannot form apatite in TB since there is no phosphate source. It cannot form apatite in AS4 since the $\mathrm{pH}$ is too low to form apatite. However, in AS7 CN shows evidence of apatite from ATR-FTIR and $\mathrm{XRD}$ spectral data. This is supported by the observation of a reduction in $\mathrm{P}$ and Ca upon immersion in AS7. It is not possible to see clearly the apatite formed in AS7 on the surface of $\mathrm{CN}$ in the cross sectional images. This contrasts with the recent study by Aleesa et al. [12-14] using a phosphate rich fluoride containing bioactive glass, where a relatively thick fluorapatite layer forms up to 20 microns thick. In that study, the apatite crystals are needle like and are highly orientated with the 002 direction perpendicular to the surface. The 002 Bragg diffraction line for apatite formed on $\mathrm{CN}$ is also about a factor of two more intense, also indicating some preferential orientation. It is thought that the 
apatite layer in $\mathrm{CN}$ may be possibly removed during the grinding and polishing of the cross sections. To overcome this problem the surface of the disks after six weeks immersion in AS7 were examined. Evidence of crystals with a random orientation and a plate like morphology were found at the surface. This morphology is often indicative of octacalcium phosphate (OCP) or a calcium deficient apatite that has formed via transformation of OCP. Closer examination of the six week FTIR spectrum in Figure 9c shows a band at $525 \mathrm{~cm}-1$ assigned to the $\mathrm{P}-\mathrm{O}$ bending of a HPO42- group that is present in OCP, but is absent in both hydroxyapatite and fluorapatite [38]. OCP, hydroxyapatite and fluorapatite all have almost identical diffraction patterns and very similar FTIR spectra. OCP has a water layer in the crystal structure that corresponds to a large diffraction spacing and a diffraction line a 4.68 o two theta that is difficult to detect. The possible presence of OCP and the lack of a needle like geometry typical of fluorapatite is surprising, since even low concentrations of fluoride ions $<1 \mathrm{ppm}$ are thought to promote direct apatite formation $[38,39]$. However $\mathrm{CN}$ releases small amounts of fluoride ( $<1 \mathrm{ppm}$ between 4 weeks and 6 weeks) which is much less than the bioactive glass studied by Aleesa et al. [14]. The amount of fluoride released by $\mathrm{CN}$ may be too low at six weeks to induce the direct formation of apatite. In the $\mathrm{CN}$ brochure [8], evidence is presented for a 0.5 micron thick orientated layer of crystals on the surface after immersion in AS for 4 weeks. The crystals have a similar morphology to those observed here but are orientated and are slightly smaller. The 002 diffraction line at 25.8 o two theta for OCP formed from solution saturated in calcium and phosphate by lijima and Onuma [39] was also observed to be significantly enhanced, also indicating preferred orientation of OCP in the 002 direction.

There was no evidence of the formation of fluorite, $\mathrm{CaF}_{2}$ formation in any immersion media with $\mathrm{CN}$ which might be expected based on the previous studies of Brauer et al. [22]. However $\mathrm{CaF}_{2}$ has a strong tendency to crystallise as small nanometer sized crystallites that are not easily detected by XRD. In AS4, there is significant release of Al for both CN and ACT with much more $\mathrm{Ca}$ released. This is a result of the acid catalysed hydrolysis of the Al-O-Si bonds in the fluoro-alumino-silicate ionomer glasses present in both $\mathrm{CN}$ and $\mathrm{ACT}$. In the absence of a low $\mathrm{pH}, \mathrm{CN}$ and $\mathrm{ACT}$ release very little $\mathrm{Al}$ and in the 
case of ACT very little $\mathrm{Ca}$ indicating that two of the glasses in ACT are probably ionomer type fluoroaluminosilicate glasses, which are not capable of forming apatite and are not bioactive in terms of the definition of being able to form apatite in body like fluids. ACT may be considered to be bioactive in terms of being to able to release fluoride in small quantities, but if this is the basis of the bioactivity, many other dental restorative materials would also be considered to be "bioactive". The higher Al release in AS4 for CN than ACT is surprising given that $\mathrm{CN}$ contains relatively little ionomer type glass, but the ionomer type glass in CN may have a higher Al:Si ratio, which would result in more acid hydrolysis $[15,16]$ and more Al release. The difference could also be accounted for by possible surface treatments of the glasses used, for example silylation [37]. The greater reactivity of the ionomer glass in $\mathrm{CN}$ is supported by SEM observations of the surfaces after immersion in AS4 that show the presence of only one of the three types of glass particles at the surface in $\mathrm{CN}$, suggesting that both the calcium fluoro-silicate and ionomer type glasses are reacting leaving the unreacted inert glass particles only at the surface.

Reaction of the glass particles of $\mathrm{CN}$, particularly at the exposed surfaces and especially on occlusal surfaces is likely to result in increased wear. It may be advantageous to laminate over the top of exposed surfaces of the $\mathrm{CN}$ to reduce wear. For example covering the surface with a conventional composite resin.

The claims of apatite formation with ACT were not substantiated in this study. The evidence presented in the Activa Technical documentation for apatite formation is based on a conference abstact where the authors sputtered coated the samples with gold then determined $\mathrm{Ca}: \mathrm{P}$ ratios by EDAX to determine apatite formation. Since sputter coating with gold interferes with $P$ determination by EDAX the validity of this is very questionable. If we define "bioactive" as having the capacity to induce apatite formation from physiological solutions ACT is not "Bioactive" within the time period of this study.

\section{Conclusions}

$\mathrm{CN}$ releases $\mathrm{Ca}_{2+}$ and $\mathrm{F}$ - ions and forms "apatite like" phase upon immersion in AS7 containing orthophosphate. In acidic media (AS4) there is evidence of the 
calcium fluoro-silicate glass particles undergoing glass degradation at the surface and to a lesser extent in AS7 and TB.

There was no evidence of any apatite like phase formation with the ACT composite in AS7 AS4 or Tris buffer or any significant glass degradation occurring within the experimental time period of six weeks despite the claims by the manufacturer. The fluoride release was significantly less than with a conventional acid base set glass ionomer cement as found by Garoushi et al. [8] despite the claims to the contrary by the manufacturer.

$\mathrm{CN}$ is a promising bioactive restorative material that has potential clinical benefits.

In the present study evidence was found for $\mathrm{CN}$ forming an apatite like phase, rather than tricalcium phosphate and $\mathrm{CaF}_{2}$ as suggested in the $\mathrm{CN}$ Technical report [6].

Further studies using both ${ }_{19} \mathrm{~F}$ and ${ }_{31} \mathrm{P}$ MAS-NMR on a version of $\mathrm{CN}$ without the Ytterbium fluoride to avoid the issue with paramagnetic line broading would be useful in distinguishing between the possible phase formed in this composite material. 


\section{References}

1. Brunthaler A, König F, Lucas T, Sperr W, Schedle A. Longevity of direct resin composite restorations in posterior teeth. Clin Oral Invest, 2003; 7:6370.

2. Ferracane JL. Resin composite - State of the art. Dental Mater, 2011; 27:29-38.

3. Collins CJ, Bryant RW, and Hodge KLV A clinical evaluation of posterior composite resin restorations: 8-year findings. Journal of Dentistry, 1998; 26 (4):311-317.

4. Valittu PK, Boccaccinni R, Hupa L, Watts DC, Editorial Bioactive dental materials - Do they exist and what does bioactivity mean? Dental Mater, 2018; 34:693-4.

5. Todd, JC, Scientific Documentation: Cention N; Ivoclar-Vivadent Press: Schaan, Liechtenstein, 2016; 1-58.

6. Jun, S.-K., Lee, J.-H. \& Lee, H.-H. The Biomineralization of a Bioactive Glass Incorporated Light-Curable Pulp Capping Material Using Human Dental Pulp Stem Cells. BioMed Research International, 2017; 1:1-9.

7.Jones J Review of Bioactive Glass: From Hench to Hybrids. Acta Biomaterialia 23, 2015; S53-S82.

8. Garoushi S, Vallittu PK and Lassila L. Characterization of fluoride releasing restorative dental materials. Dental Mater, 2017; 37:293-300.

9. Ilie N, Comparative Effect of Self- or Dual-Curing on Polymerization Kinetics and Mechanical Properties in a Novel, Dental-Resin-Based Composite with Alkaline Filler. Materials, 2018; 11:108.

10. Deepak S, Nivedhitha MS, Proximal contact tightness between two different restorative materials - An in vitro study. Journal of Advanced Pharmacy Education \& Research, 2017; 7:153-6

11. Samanta S, Kumar Das UK, Mitra A Comparison of Microleakage In Class V Cavity Restored with Flowable Composite Resin, Glass lonomer Cement and Cention N. Imperial Journal of Interdisciplinary Research (IJIR), 2017; 3:180-183.

12. Al-eesa NA, Johal A, Hill RG, and Wong FSL. Fluoride Containing Bioactive Glass Composite For Orthodontic Adhesives - formation and characterisation of apatites using MAS-NMR and SEM. Dental Mater, 2019; 35:597-605. 
13. Al-eesa NA, Johal A, Hill RG, Wong FSL. Fluoride containing bioactive glass composite for orthodontic adhesives - apatite formation properties Dental Mater, 2018; 34:1127-33.

14. Al-eesa NA, Johal A, Hill RG, Wong FSL. Fluoride containing bioactive glass composite for orthodontic adhesives - ion release properties. Dental Mater, 2017; 33:11324-1329.

15. Hill RG, Wilson AD. Some Structural Aspects of Glasses Used in lonomer Cements. Glass Technology,1988; 29:150-8.

16. Griffin S, Hill RG, Influence of glass composition on the properties of glass polyalkenoate cements: Part II - Influence of phosphate content. Biomaterials (2000); 21:399-403.

17. Gentleman E, Stevens MM, Hill RG, and Brauer DS. Surface properties and ion release from fluoride-containing bioactive glasses promote osteoblast differentiation and mineralization in vitro. Acta Biomaterialia, 2013; 9:57715779

18. Brauer DS. Bioactive Glasses -Structure and Properties. Angewandte Chemie, 2015; 54:4160-4181.

19. Shahid S, Hassan U, Billington RW, Hill RG. Glass ionomer cements: Effect of Strontium substitution on aesthetics radio-opacity and ion release. Dental Mater, 2014; 30:308-331

20. Serra J, González P, Liste S, Serra C, Chiussi S, León B. FTIR and XPS studies of bioactive silica based glasses. J Non Cryst Solids, 2003;332:20-7.

21. Fredholm FC, Karpukhina N, Brauer DS, Jones JR, Law RV, Hill RG. Influence of Strontium for calcium substitution in bioactive glasses on degradation ion release and apatite formation. J. R. Soc. Interface, 2012; 9:880-889.

22. Brauer DS, Karpukhina N, O'Donnell M, Law RV, and Hill RG. Fluoride containing bioactive glasses: Effect of glass design and structure on degradation, $\mathrm{pH}$ and apatite formation in simulated body fluid. Acta Biomaterialia, 2010; 6:3275-82.

23. Lynch E, Brauer DS, Karpukhina N, Gillam DG, Hill RG, Multicomponent bioactive glasses of varying fluoride content for treating dentin hypersensitivity Dental Materials, 2012; 18:168-178.

24. Liu J, Simon Rawlinson CSF, Hill RG, Fortune F. Fluoride incorporation in high phosphate containing bioactive glasses and in vitro osteogenic, angiogenic and antibacterial effects. Dental Materials, 2016; 32;412-422. 
25. De Caluwéa T, Vercruyssea CWJ, Declercqb HA, Schaubroeckc D, Verbeecka RMH, Martens LC. Bioactivity and biocompatibility of two fluoride containing bioactive glasses for dental applications Dental Materials, 2016; 32:1414-28.

27. Khvostenko, TJ, Hilton JL, Ferracane JC, Mitchell JJ. Kruzic Bioactive glass fillers reduce bacterial penetration into marginal gaps for composite restorations. Dental Materials, 2015; 31:701-10.

28.Yang SY, Kim SH, Choi SY, Kim KM. Acid Neutralizing Ability and Shear Bond Strength Using Orthodontic Adhesives Containing Three Different Types of Bioactive Glass. Materials, 2016; 9:125.

29. Davis HB, Gwinner F, Mitchell JC, Ferracane JL. lon release from, and fluoride recharge of a composite with a fluoride-containing bioactive glass. Dental Materials, 2014; 30:1187-94.

30. Tezvergil-Mutluay A, Seseogullari-Dirihan R, Feitosa VP, Cama G, Brauer DS, Sauro S, Effects of Composites Containing Bioactive Glasses on Demineralized Dentin. J. Dent Res, 2017; 96:999-1005.

31. Edén M,. The split network analysis for exploring composition-structure correlations in multi-component glasses: I. Rationalizing bioactivitycomposition trends of bioglasses. Journal of Non-Crystalline Solids, 2011; 357:1595.

32. O'Donnell MD, Watts SJ, Law RV, Hill RG, The effect of phosphate content on the bioactivity of soda-lime-phosphosilicate glasses. J. Mater Sci-Mat in Med, 2009; 20:1611-1618.

33. Mneimne M, Hill RG, Bushby A, and Brauer DS. High phosphate contents significantly increase apatite formation of fluoride-containing bioactive glasses. Acta Biomater, 2011; 7:1827-34.

34. Fischer P, Grabher UK, Holand K, Mozner W, Rheinberger V, Rumphorst A, Salz U and Schweiger M, Polymerisable Composite Material EP0923925 A2. 1997;

35. Hill RG, Brauer DS, Predicting the bioactivity of glasses using the network connectivity or split network models. Journal of Non-Crystalline Solids, 2011; 357:3884-3887.

36. Duminis T, Shahid S, NKarpukhina NG, Hill RG, Predicting refractive index of fluoride containing glasses for aesthetic dental restorations. Dental Materials, 2018 34:e83-e88.

37. Lippo OO, Lassilaa V, Kumbuloglu O, Vallittu P, Bioactive glass particulate filler composite: Effect of coupling of fillers and filler loading on some physical properties. Dent. Mater, 2014; 30:570-577. 
38. Markovic M, Chow LC. An Octacalcium Phosphate Forming Cement. J Res Natl Inst Stand Technol. 2010; 115:257-265.

39. lijima $\mathrm{M}$ and Onuma $\mathrm{K}$ Roles of Fluoride on Octacalcium Phosphate and Apatite Formation on Amorphous Calcium Phosphate Substrate Cryst. Growth Des, 2018; 18:2279-2288.

40. van Dijkena JWV, Pallesen U, Benetti A. A randomized controlled evaluation of posterior resin restorations of an altered resin modified glassionomer cement with claimed bioactivity. Dent Mater, 2019; 35:335-343. 
Tables

Table 1 Details of the Composites Studied

\begin{tabular}{|l|l|l|l|}
\hline Composite & $\begin{array}{l}\text { Batch } \\
\text { No }\end{array}$ & Manufacturer & Description \\
\hline Cention N & WT27641 & $\begin{array}{l}\text { Ivoclar Vivadent } \\
\text { Benderestrasse 2 } \\
\text { Schaan Lichtenstein }\end{array}$ & $\begin{array}{l}\text { Composite resin containing a } \\
\text { Mixture of Glasses including an } \\
\text { Alkaline Calcium fluorosilicate glass }\end{array}$ \\
\hline Activa & 170720 & $\begin{array}{l}\text { Pulpdent Corp } \\
80 \text { Oakland St } \\
\text { Watertown } \\
\text { MA02472 } \\
\text { USA }\end{array}$ & $\begin{array}{l}\text { A Composite resin claimed to be } \\
\text { bioactive }\end{array}$ \\
\hline
\end{tabular}

Table 2 Glass Composition From EP 0923925 A2 [34] Compared to that Studied by Al-eesa et al.[12-14].

\begin{tabular}{|c|c|c|c|c|c|c|c|}
\hline Glass & $\mathrm{SiO}_{2}$ & $\mathrm{P}_{2} \mathrm{O}_{5}$ & $\mathrm{CaO}$ & $\mathrm{Na}_{2} \mathrm{O}$ & $\mathrm{CaF}_{2}$ & $\mathrm{NC}$ & $\mathrm{RFI}$ \\
\hline $\begin{array}{c}\text { Example } \\
\mathbf{7}\end{array}$ & 0.48 & 0.00 & 0.31 & 0.08 & 0.12 & 2.36 & 1.53 \\
\hline $\begin{array}{c}\text { Al-eesa et } \\
\text { al. [12-14] }\end{array}$ & 0.35 & 0.06 & 0.43 & 0.06 & 0.1 & 2.19 & 1.57 \\
\hline
\end{tabular}

${ }_{+} \mathrm{RFI}$ is the refractive index calculated according to Duminis et al.[36].

${ }^{*} \mathrm{NC}$ is the network connectivity calculated according to Hill and Brauer [35]. 


\section{List of Figures}

Figure 1 Back scattered SEM of CN. The arrows indicate Ytterbium fluoride and three different compositions of glass particles.

Figure 2 Back scattered SEM of ACT with two different glass particle compositions.

Figures $3 a$ to $3 \mathrm{c}$ pH changes of $\mathrm{CN}(\bullet)$ and ACT $(\bullet)$ in TB, AS4 and AS7 respectively.

Figure 4 Measured Cumulative Calcium in TB for $\mathrm{CN}(\square)$ and ACT(•).

Figure 5a Cumulative $\mathrm{Ca}$ and $\mathrm{P}$ above back ground for $\mathrm{CN}$ and $\mathrm{ACT}$ in AS4. CN Ca (ロ) $\mathbf{P}(\diamond), \quad$ ACT Ca $(\square) \quad P(\diamond)$.

Figure 5b Cumulative P lost against square root time in AS7. CN (口) ACT $(\nabla)$.

Figure 6 Cumulative Al release plotted against square root time.

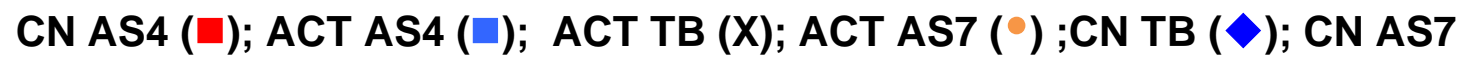
$(\bullet)$.

Figure 7 Si Release into TB. CN( $\square)$ ACT (•).

Figure 8 Measured cumulative Fluoride into TB, AS4 and AS7 for CN ( and $\mathrm{ACT}(\bullet)$.

Figure 9 ATR-FTIR spectra for CN after immersion in TB, AS4 and AS7 for time periods up to 6 weeks.

Figure 10 ATR-FTIR spectra for ACT after immersion in TB, AS4 and AS7 for time periods up to 6 weeks. 
Figure $11 \mathrm{XRD}$ patterns of Cention $\mathrm{N}$ before immersion ( $\left.{ }^{\circ}\right)$, after 2 weeks $(\cdot)$ and 6 weeks $(\cdot)$ in $A S 7 . Y=\mathrm{YbF}_{3}, \mathrm{~A}=$ Apatite.

Figure 12 SEM Micrographs of $\mathrm{CN}$ a) before Immersion; b) after immersion in AS4 for 2 weeks; c) after immersion in AS4 for six weeks; d) a close-up of the reacted surface layer from Figure 12c; e) before immersion; f) after immersion in AS7 2 weeks; and g) after immersion in AS7 6 weeks. The dashed line indicates the thickness of the reacted layer in the composite disk.

Figure 13 Top down surface SEM of CN after 6 weeks immersion in AS7 showing plate like crystal formation. 


\section{Figures}

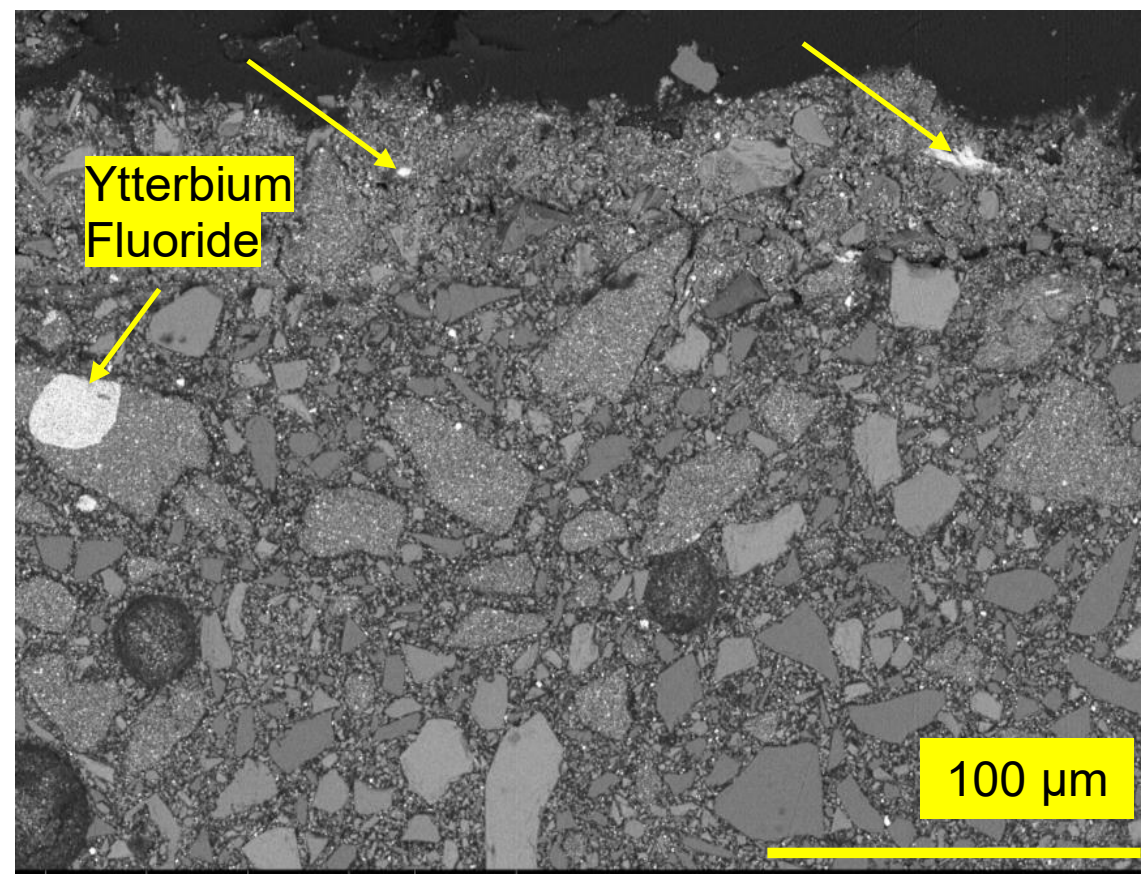

Figure 1 Back scattered SEM of CN. The arrows indicate Ytterbium fluoride and three different compositions of glass particles. 


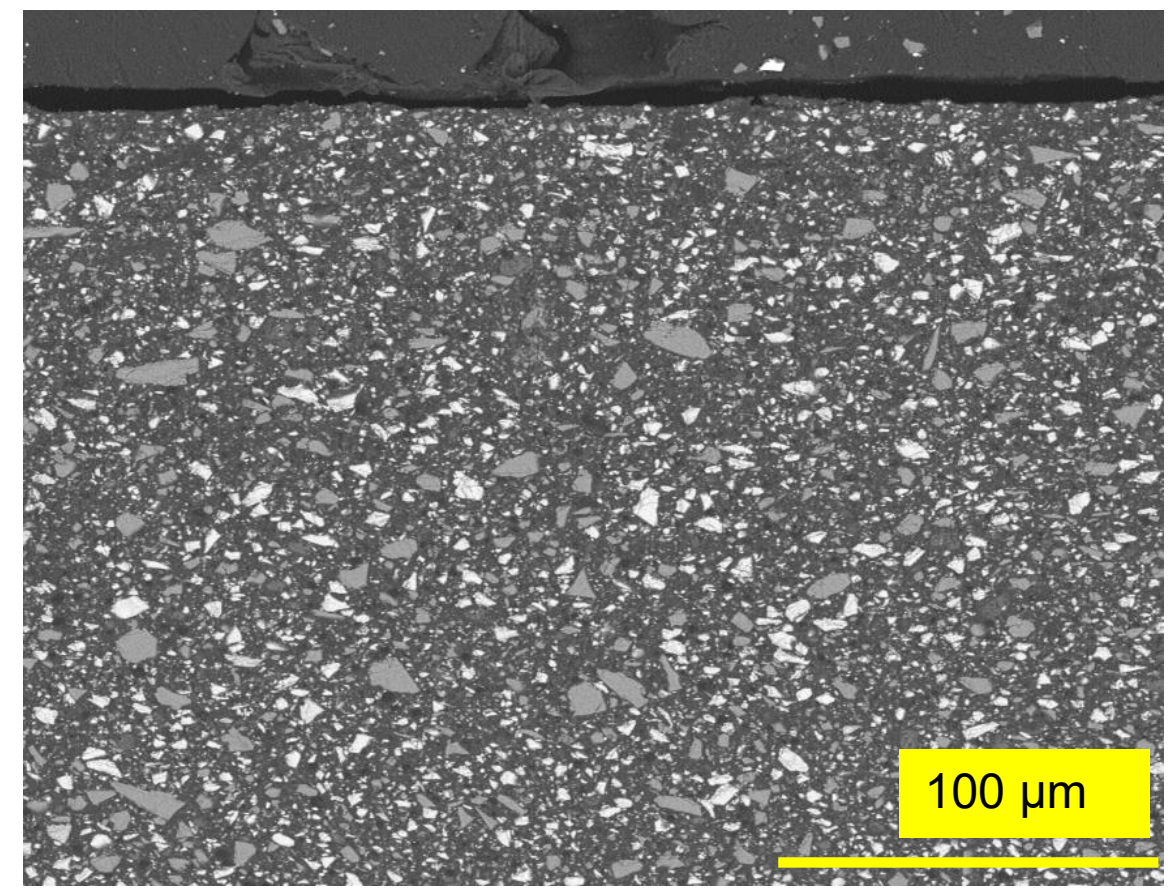

Figure 2 Back scattered SEM of ACT with two different glass particle compositions. 

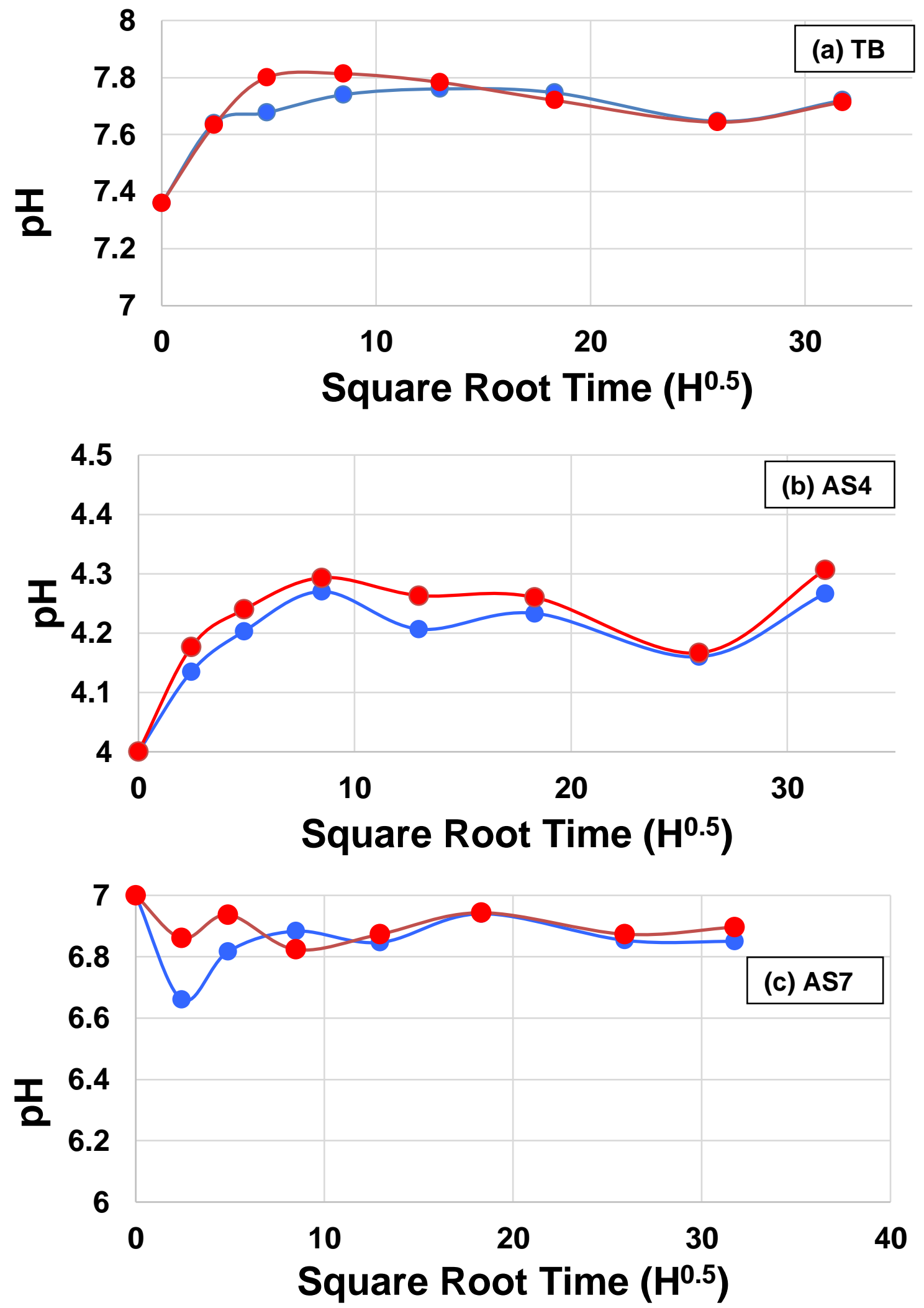

Figures $3 \mathrm{a}$ to $3 \mathrm{c} \mathrm{pH}$ changes of $\mathrm{CN}(\cdot)$ and ACT $(\cdot)$ in TB, AS4 and AS7 respectively. 


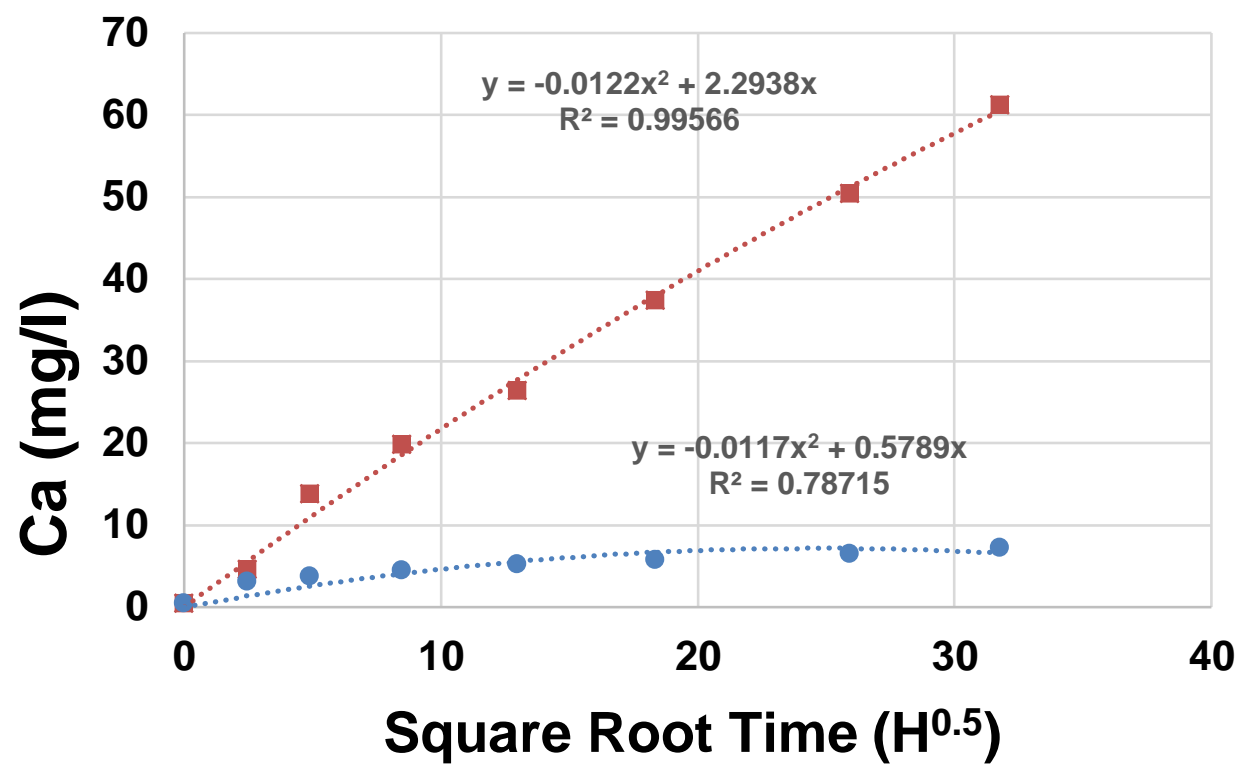

Figure 4 Measured Cumulative Calcium in TB for CN ( $\square)$ and ACT(•).

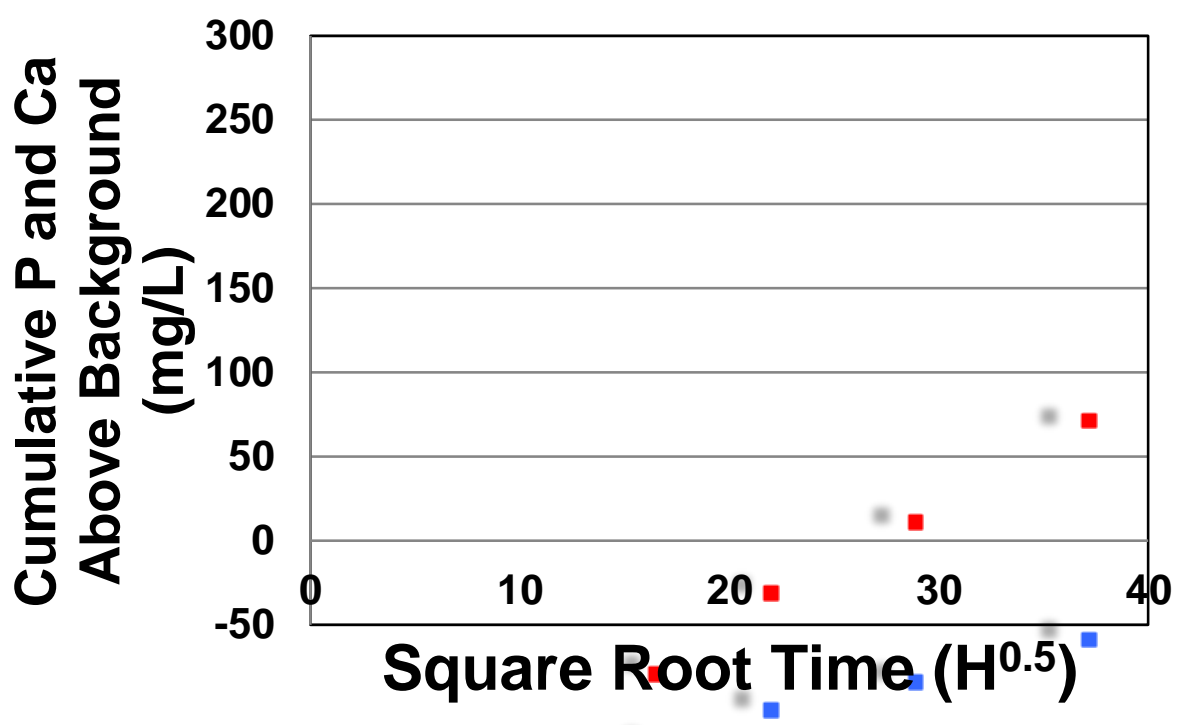

Figure 5a Cumulative $\mathrm{Ca}$ and $\mathrm{P}$ above back ground for $\mathrm{CN}$ and $\mathrm{ACT}$ in AS4. CN Ca $(\square) \mathrm{P}(\diamond), \quad$ ACT Ca $(\square) \mathrm{P}(\diamond)$. 


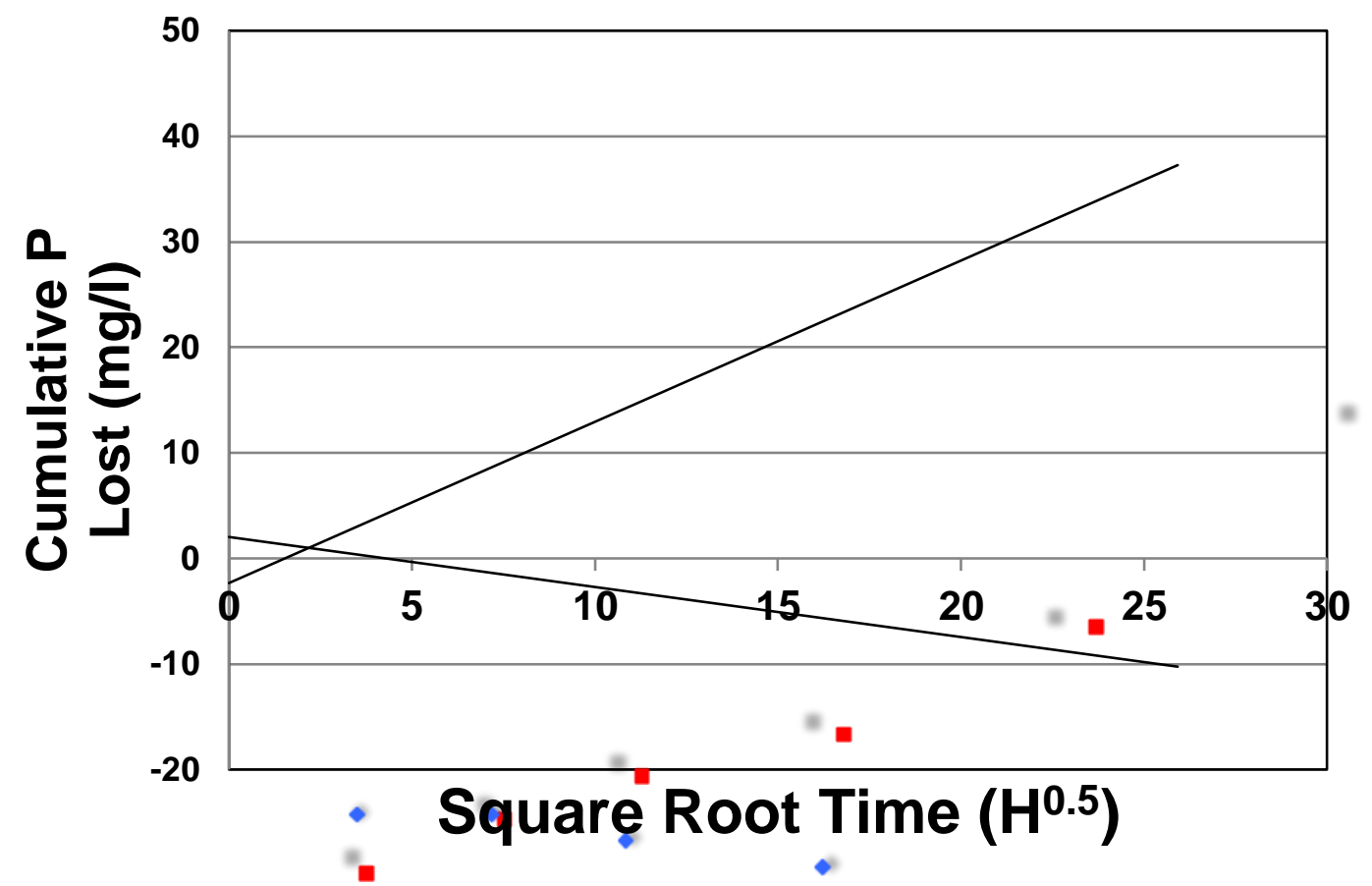

Figure 5b Cumulative P lost against square root time in AS7. CN ( $\square$ ) ACT $(\diamond)$. 


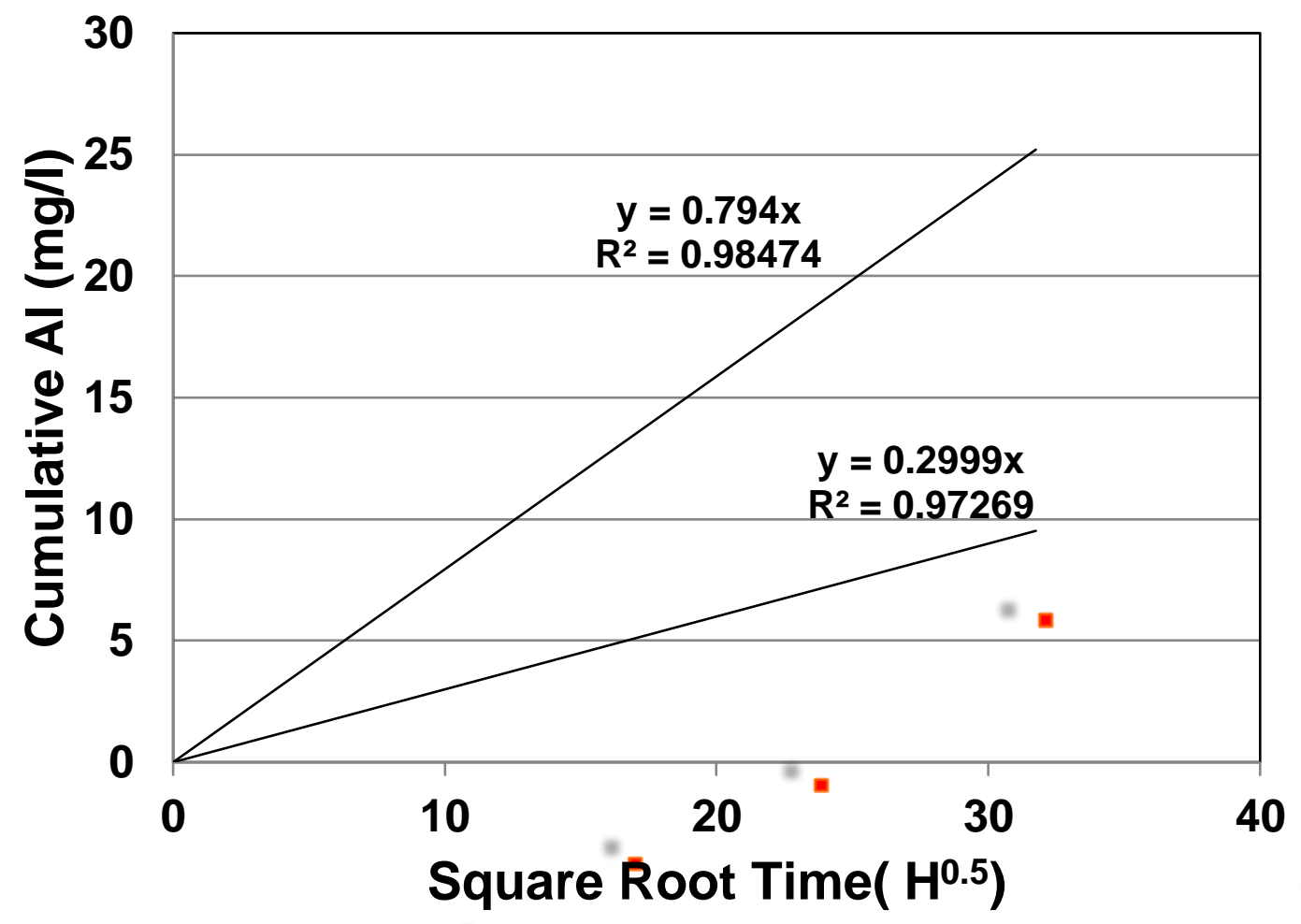

Figure 6 Cumulative Al release plotted against square root time.

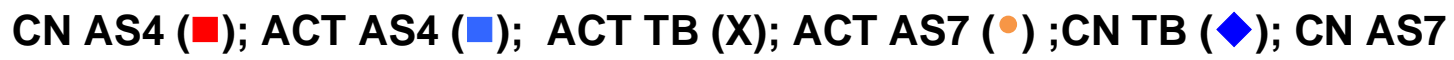
$(\bullet)$. 


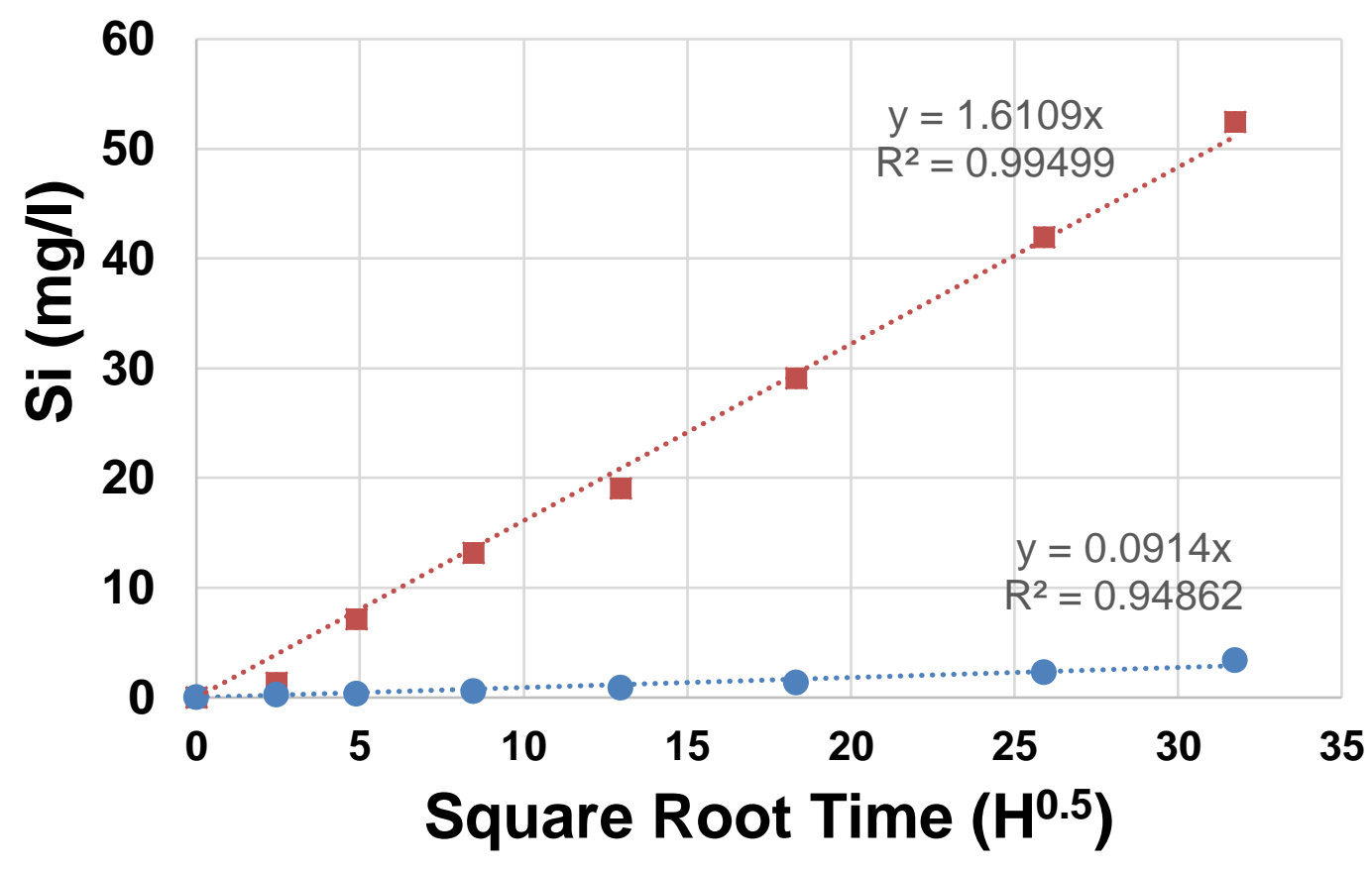

Figure 7 Si Release into TB. CN( $\square)$ ACT (॰). 

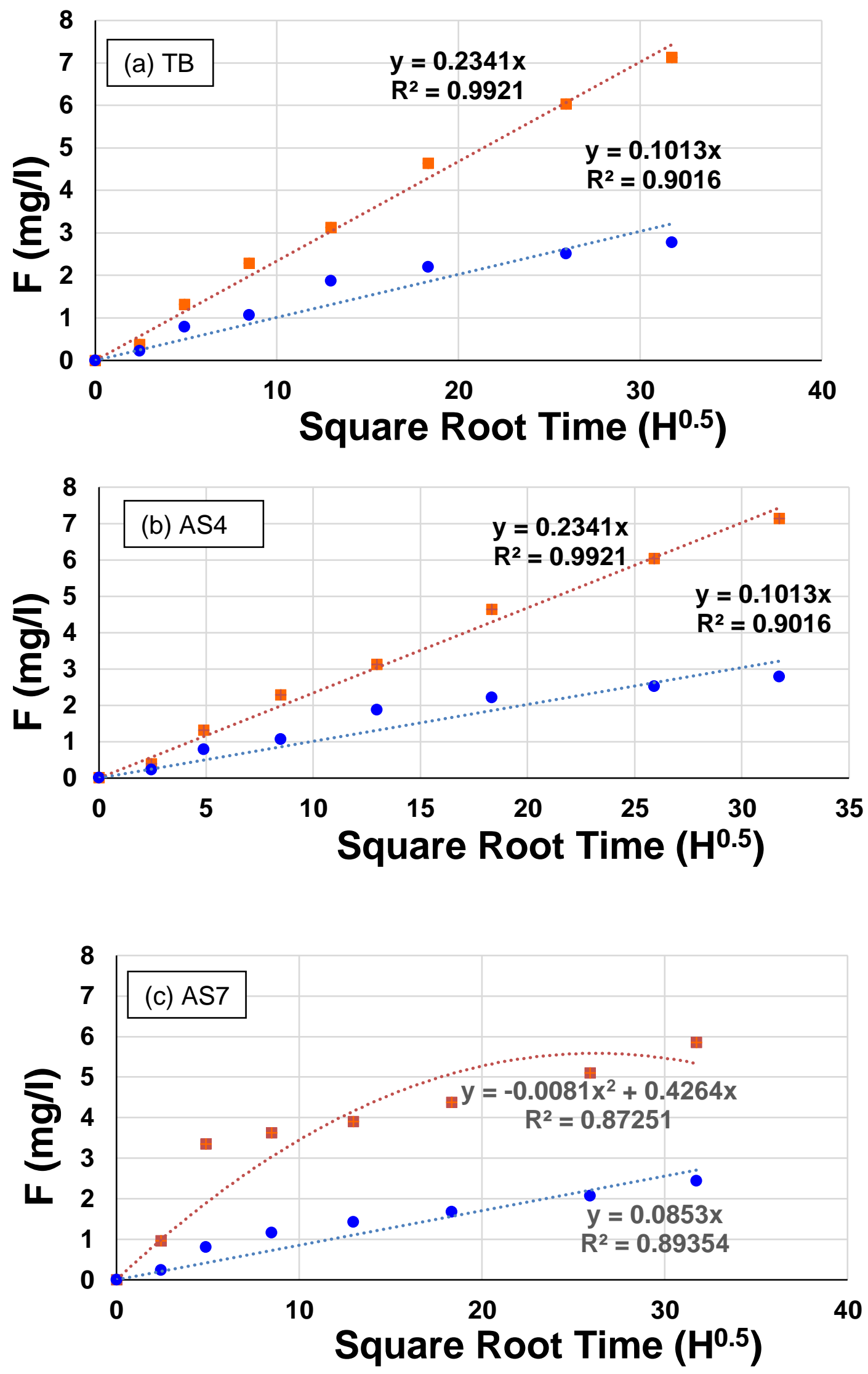

Figure 8 Measured cumulative Fluoride into TB, AS4 and AS7 for CN (घ) and $\mathrm{ACT}(\bullet)$. 

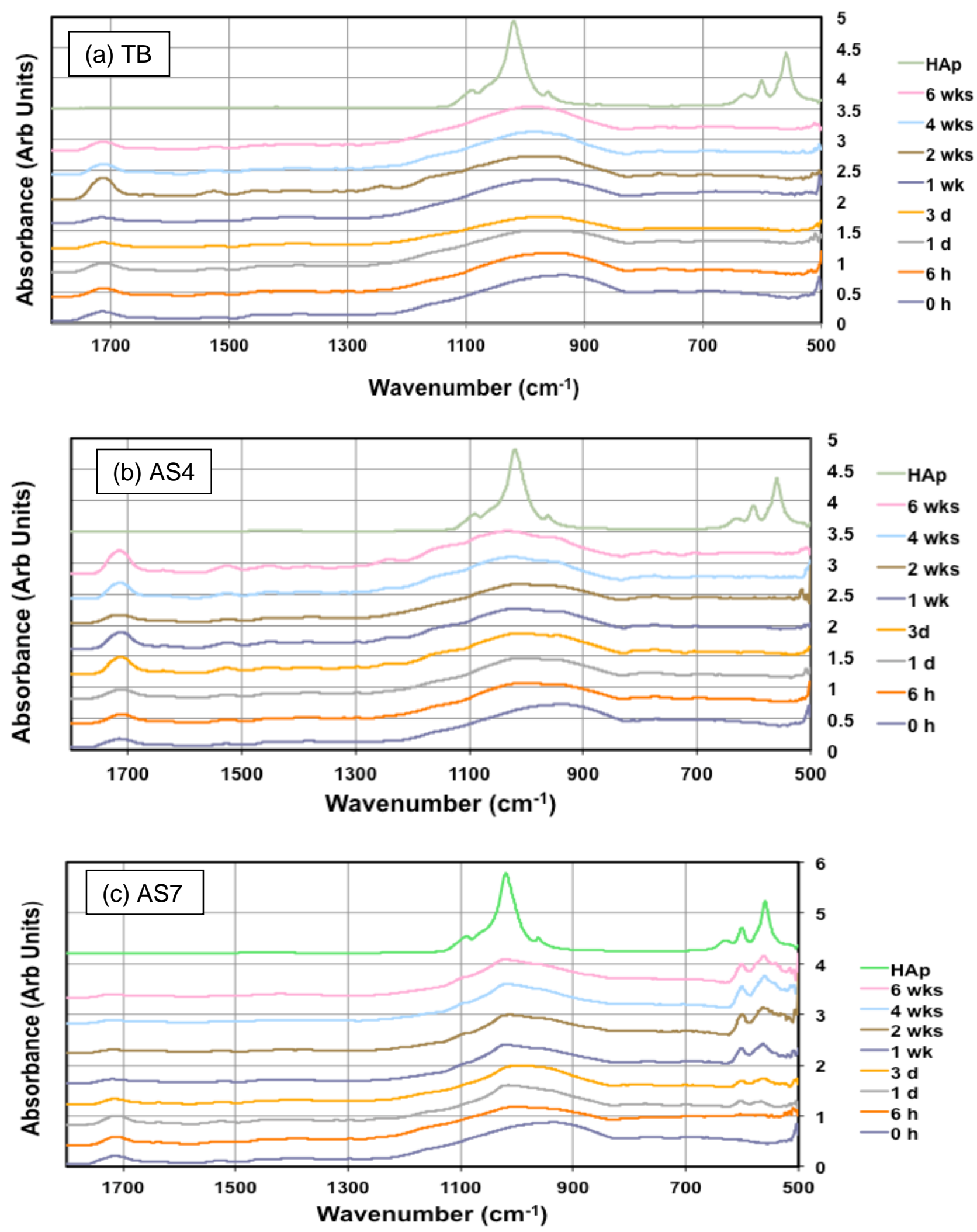

Figure 9 ATR-FTIR spectra for CN after immersion in TB, AS4 and AS7 for time periods up to 6 weeks. 

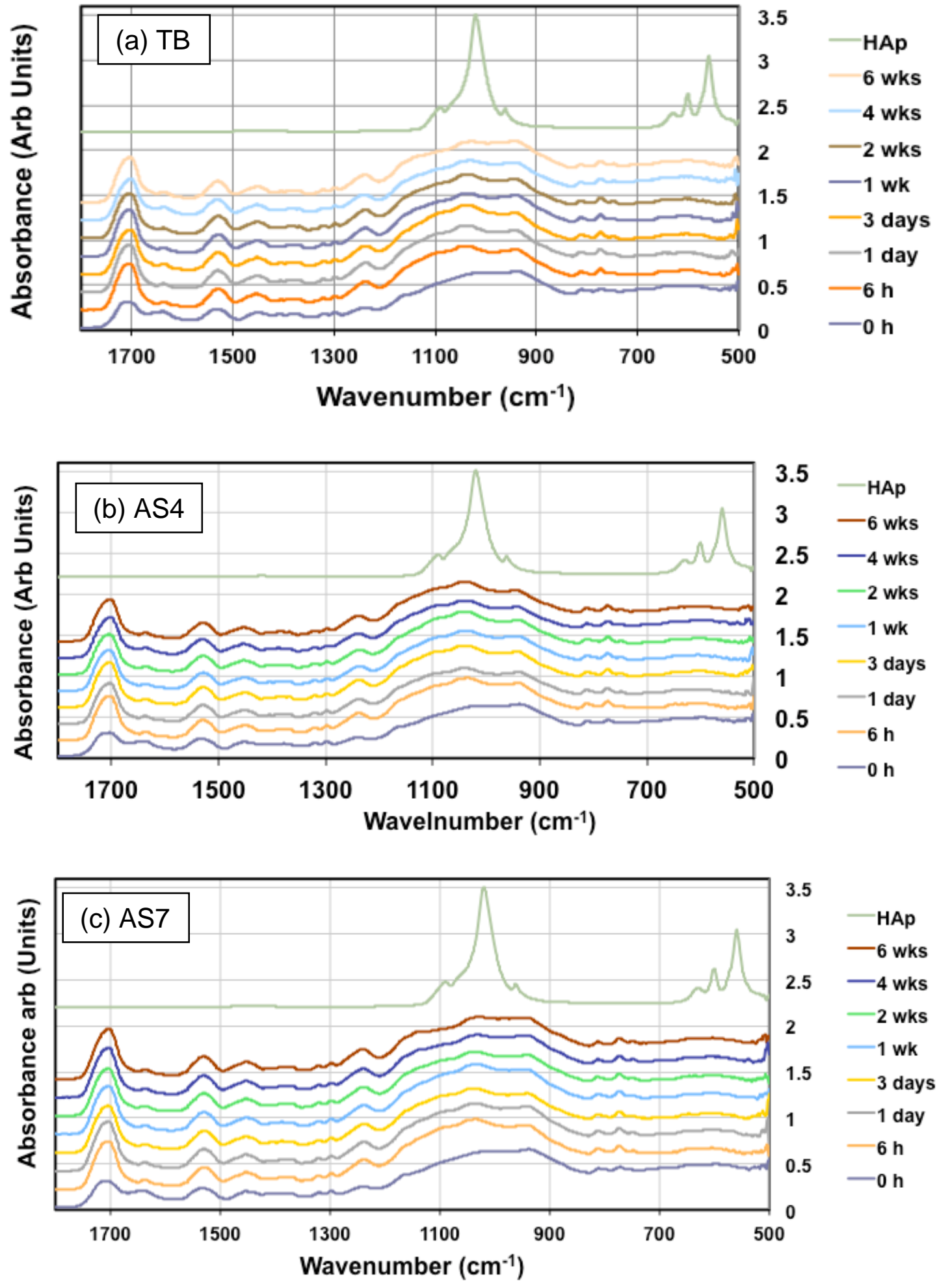

Figure 10 ATR-FTIR spectra for ACT after immersion in TB, AS4 and AS7 for time periods up to 6 weeks. 


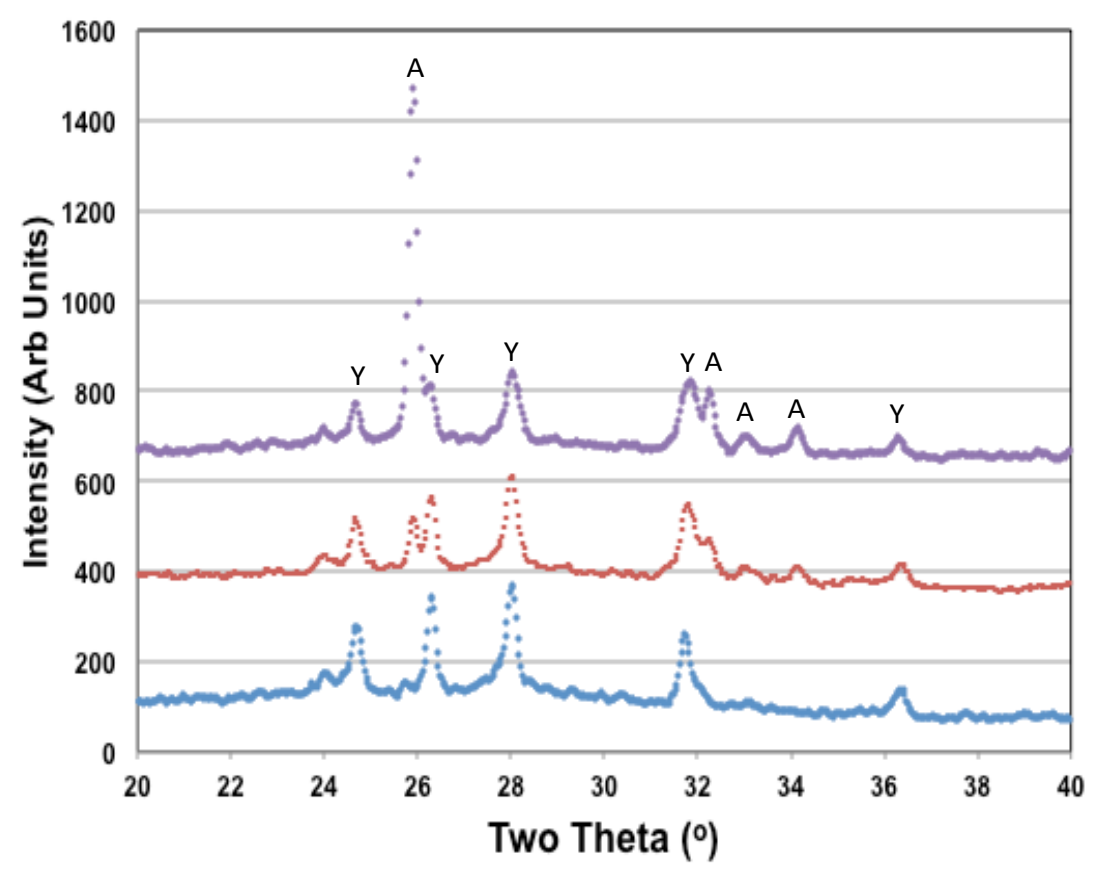

Figure 11 XRD patterns of Cention $\mathrm{N}$ before immersion ( $\left.{ }^{\circ}\right)$, after 2 weeks $(\cdot)$ and 6 weeks $\left({ }^{\circ}\right)$ in $A S 7 . Y=\mathrm{YbF}_{3}, \mathrm{~A}=$ Apatite. 

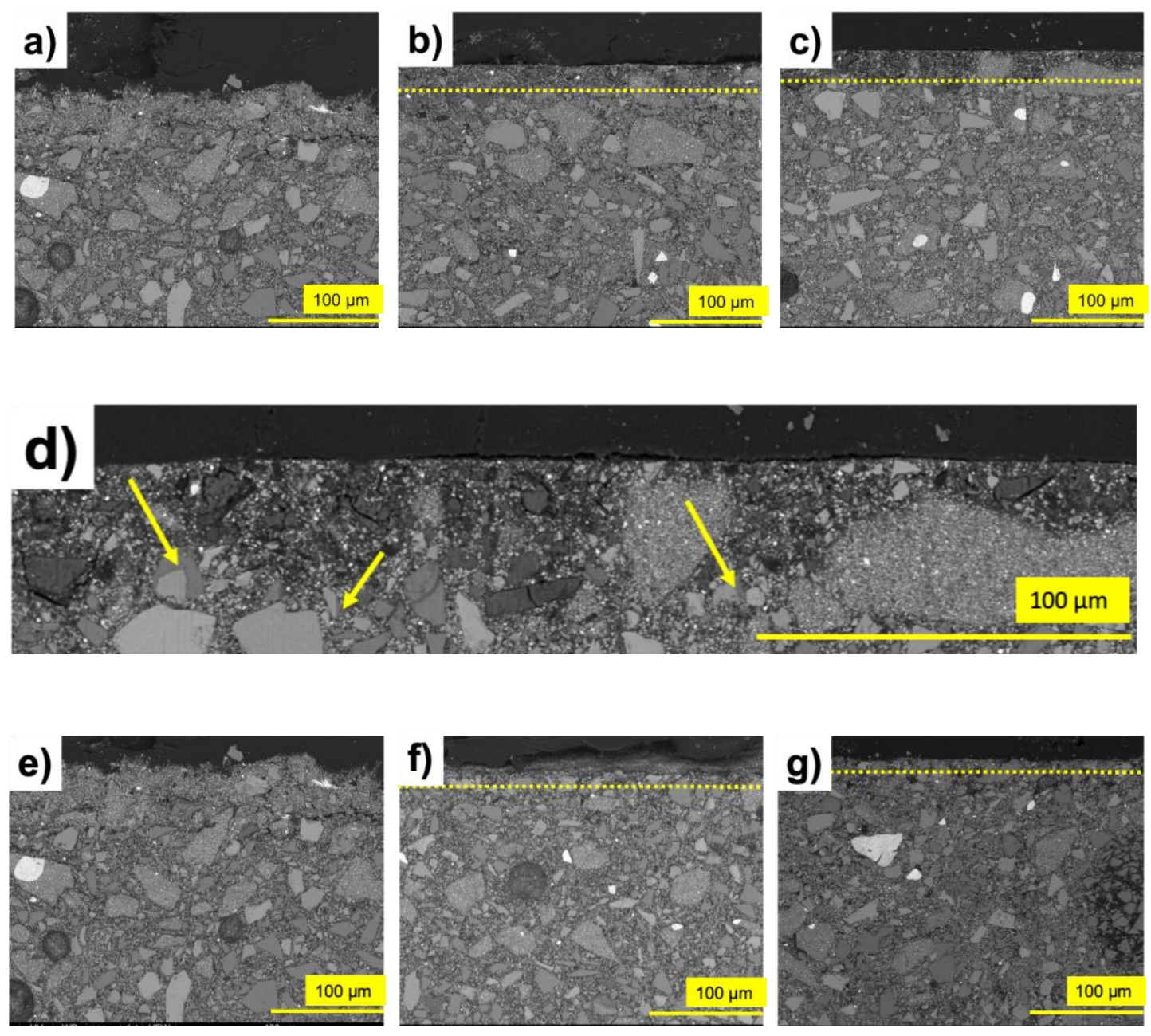

Figure 12 SEM Micrographs of $\mathrm{CN}$ a) before Immersion; b) after immersion in AS4 for 2 weeks; c) after immersion in AS4 for six weeks; d) a close-up of the reacted surface layer from Figure 12c; e) before immersion; f) after immersion in AS7 2 weeks; and g) after immersion in AS7 6 weeks. The dashed line indicates the thickness of the reacted layer in the composite disk. 


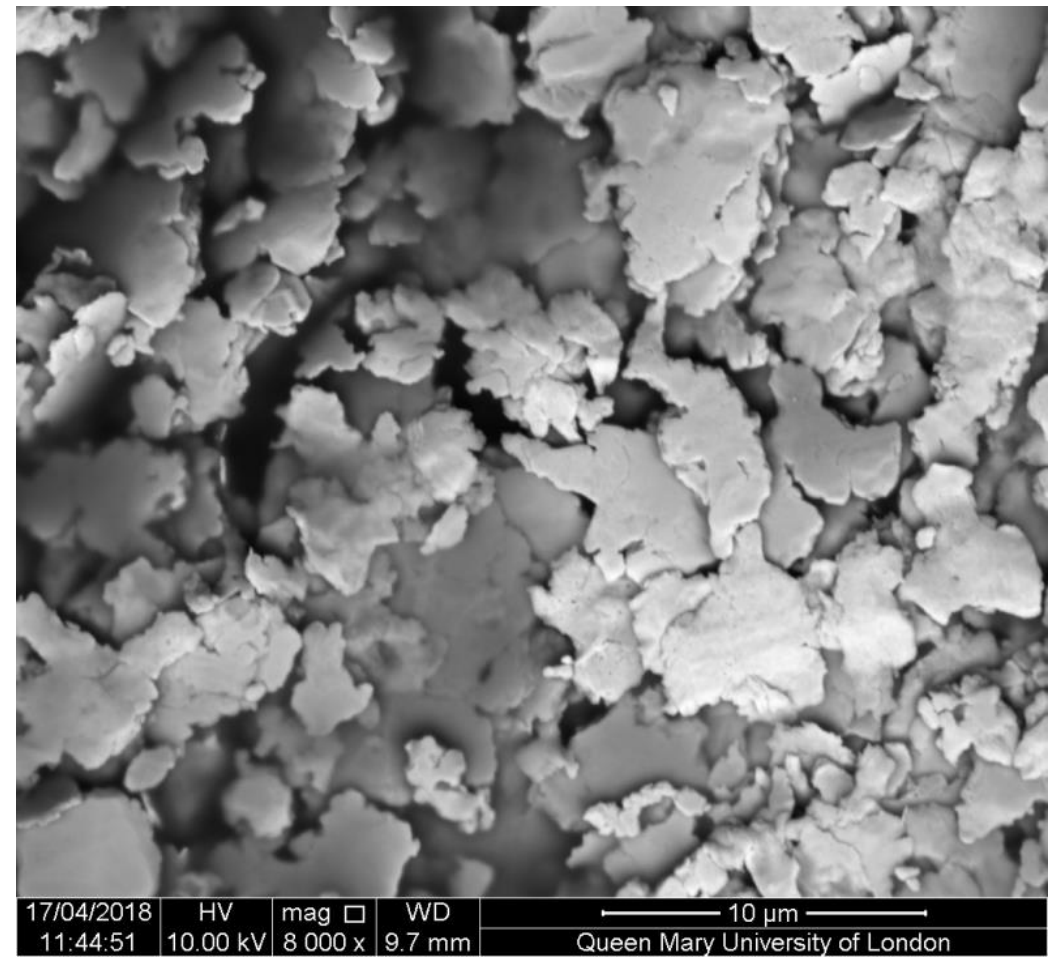

Figure 13 Top down surface SEM of CN after 6 weeks immersion in AS7 showing plate like crystal formation. 